\title{
PENINGKATAN KETERAMPILAN MENULIS PUISI DENGAN MENGGUNAKAN MODEL PEMBELAJARAN EXAMPLE DAN NON-EXAMPLE SISWA KELAS X SMA NEGERI 10 KOTA TERNATE
}

\author{
${ }^{1}$ Sulami Sibua, Firdha Rahmadhany ${ }^{2}$ \\ sulamisibua71@gmail.com; firdha.rahma22@gmail.com \\ ${ }^{1,2}$ Program Studi Pendidikan Bahasa dan Sastra Indonesia, Universitas Khairun
}

\begin{abstract}
Abstrak
Penelitian ini dilakukan dengan tujuan untuk mengetahui bagaimana kemampuan siswa dalam menulis puisi siswa kelas X SMA Negeri 10 Kota Ternate dan bagaimana peningkatan kemampuan menulis puisi menggunakan model Example dan Non-Example siswa kelas X SMA Negeri 10 Kota Ternate. Metode yang digunakan dalam penelitian ini adalah deskriptif kuantitaif dan instrumen yang digunakan adalah observasi, wawancara, tes dan dokumentasi. Berdasarkan hasil penelitian Peningkatan Keterampilan Menulis Puisi dengan Menggunakan Model Example dan Non-Example siswa kelas X SMAN 10 Kota Ternate yang terdiri dari 25 siswa dapat diketahui bahwa siswa mampu menulis puisi dengan menggunakan model Example dan NonExample, hal ini diketahui dari hasil penelitian yang terdapat ada lembar kerja pada Pre Test dan Post Ters yang mengalami peningkatan, pada pre test dengan jumlah nilai 1.005 dengan nilai rata-rata 40.2 dari hasil tes awal sebanyak 23 siswa 92\% tidak mencapai (KKM). Sedangkan pada hasil post test dalam menulis puisi menggunakan model Example dan Non-Example siswa kels X SMA Negeri 10 Kota Ternate, dengan nilai 1.590 dengan nilai rata-rata 63.6 sebanyak 17 siswa $68 \%$ sudah mencapai (KKM).
\end{abstract}

Kata Kunci: Menulis, Puisi, example non example, keterampilan

\begin{abstract}
This research was conducted wiht the aim to find out how the students ability in writing poetry in class X SMAN 10 Ternate city and how to improve the ability to write poetry using the example and non-example models of grade X students of SMAN 10 ternate city. The methoud used in this research is descriptive quantitative and the instruments used are observation, interviews, tests and documentation.Based on the results of the studi, poetry writing skills improvement using example and non-example models class X students of SMAN 10 Ternate city consisting of 25 students can be seen that students are able writing poetry using model example and nonexample, this is known from the results of research that there are worksheets on the pretest and postets which have increased, in the pretest and postest which have in creased, in the pretest with atotal value of 1.005 with and average value of 40,2 whereas the results of the posttest in the write poetry using the example and nonexample models class $X$ students of SMAN 10 Ternate city, with a value of 1.550 demgas an average value of 63,6 as many 23 students 68\% have achieved (KKM) from the initial test results of 17 studens $92 \%$ did not $\operatorname{reach}(K K M)$.
\end{abstract}

Keywords: Write, Poetry, example non example, skill

\section{PENDAHULUAN}

Menulis ialah menurunkan atau melukiskan lambang-lambang grafik yang menggambarkan suatu bahasa yang dipahami oleh seseorang, sehingga orang-orang lain dapat membaca lambanglambang grafik tersebut kalau mereka memahami bahasa dan gambar grafik itu (Guntur, 2008). Sebab itu menulis merupakan suatu keterampilan yang sangat penting yang tidak dapat dipisahkan dari proses belajar mengajar. Sebagai suatu keterampilan, menulis memang harus melalui proses belajar dan berlatih. Semakin sering belajar dan berlatih, tentu semakin cepat terampil. Seorang yang sudah biasa menuliskan sebuah ide, gagasan, pendapat, atau perasaannya, dia tidak akan mengalami kesulitan ketika diminta untuk menulis. Berbeda halnya dengan seorang yang jarang atau bahkan sama sekali 
tidak pernah membuat sebuah karya tulis, tentunya akan mengalami banyak kesulitan ketika diminta untuk menulis terutama menulis puisi (Wardhana \& Ardianto, 2007).

Menulis puisi memang bukan hal yang mudah, karena puisi memiliki keunikan tersendiri yang terletak pada bahasa yang digunakan, karena bahasa yang digunakan puisi berbeda dengan bahasa yang dipakai dalam drama dan fiksi. Namun, pembelajaran menulis puisi perlu diajarkan kepada siswa sekolah dasar sampai tingkat menengah ke atas, karena pembelajaran menulis puisi dapat dipakai untuk melatih kepekaan seseorang terhadap nilai-nilai kehidupan di sekitar manusia (Guntur, 2008).

Puisi merupakan bentuk karya sastra yang diungkapkan melalui pikiran dan perasaan penyair secara imajinatif, Penyair mencurahkan segala perasaan dan pikiran yang kemudian memanfaatkan kreativitas penyair dan diwujudkan melalui medium bahasa (Suhartono, 2012). Oleh karena itu, penyair memanfaatkan diksi, gaya bahasa, ritma, citraan, secara retorika sebagai faktor kebahasaan yang berhubungan dengan struktur kata atau kalimat dalam puisinya .

Salah satu alternatif dalam menulis puisi ialah dengan menggunakan model pembelajaran Example Non-Example, yaitu menghadirkan objek sebagai inspirasi menulis siswa untuk membantu siswa mengatasi permasalahan dalam menulis puisi (Aqib, 2013). Example Non-Example dapat dieksplorasikan untuk membantu meningkatkan kemampuan menulis puisi.

Example Non-Example dapat digunakan dalam pembelajaran keterampilan menulis puisi karena dengan melihat objek atau sampel, siswa akan terbawa dalam imajinasi mereka dan hal tersebut diharapkan dapat membantu siswa menuangkan ide kreatif serta gagasan ke dalam bentuk puisi (Kurniasih \& Sani, 2015). Hasil penelitian (Rahman, 2017, 2013; Rahman \& Ahmad, 2017; Rahman \& Latif, 2020) menunjukkan bahwa guru harus mampu dan terampil dalam memilih model, strategi dan metode yang tepat sesuai dengan materi yang diajarkan. Sehingga penelitian ingin mengungkap penggunaan model pembelajaran example non example untuk meningkatkan keterampilan menulis pada siswa kelas X SMAN 5 kota Ternate. Penggunaan model ini diharapkan dapat mengembangkan minat siswa, dan membantu siswa menafsirkan serta mengingat isi pelajaran yang berkenaan dengan gambar-gambar yang ada.

\section{METODE PENELITIAN}

Metode penelitian yang digunakan oleh peneliti dalam penelitian ini adalah metode deskriptif kuantitatif. Metode kuantitatif dapat diartikan sebagai metode penelitian yang berlandasan pada filsafat positivisme, digunakan untuk meneliti pada populasi atau sampel tertentu, teknik penggambilan sampel pada umumnya dilakukan secara random, pengumpulan data menggunakan instrument penelitian, analisis data bersifat kuantitatif/statistik dengan tujuan untuk menguji hipotesis yang telah ditetapkan (Sugiyono, 2013).

Desan Penelitian

\section{$\mathrm{O}_{1} \times \mathrm{O}_{2}$}

Keterangan:

$\mathrm{O}_{1}$ : Nilai Pretest (Teks awal)

$\mathrm{X}$ : Model Pembelajaran (Example dan Non-Example)

$\mathrm{O}_{2}$ :Nilai posttest (Teks akhir)

(Sugiyono, 2013). 


\section{Populasi dan sampel}

Menurut Sugiyono, (2013), populasi adalah wilayah generalisasi yang terdiri atas objek atau subjek yang mempunyai kualitas dan karakteristik tertentu yang diterapkan oleh peneliti untuk dipelajari dan kemudian ditarik kesimpulan. Adapun populasi dalam penelitian ini adalah keseluruhan objek dalam lokasi penelitian. Jadi populasi yang diambil dalam penelitian ini adalah keseluruhan siswa di kelas X SMA Negeri 10 Kota Ternate, tahun ajaran 2019 yang berjumlah 144 siswa. Sementara, sampel adalah sebagian dari populasi atau wakil populasi yang diteliti. Dinamakan penelitian sampel apabila kita bermaksud untuk menggeneralisasikan hasil penelitian sampel (Arikunto, 2002). Sampel adalah sebagian dari populasi itu. Sedangkan sampel dalam penelitian ini menggunakan Sample Random Sampling adalah siswa kelas X SMA Negeri 10 Kota Ternate yang berjumlah 25 siswa. Instrumen penelitian yang digunakan dalam pembelajaran menulis puisi menggunakan model pembelajaran Example Non-Example adalah observasi, wawancara, dokumentasi, dan tes.

Teknik pengumpulan data yang dilakukan dalam penelitian ini diuraikan sebagai berikut:

1. Observasi. Teknik observasi atau pengamatan yang telah berpengalaman mengarahkan perhatiannya pada jenis kegiatan dan peristiwa tertentu ysng memberikan informasi dan pandangan yang benar-benar berguna (Moleong, 2019). Teknik observasi dilakukan untuk menemukan masalah penelitian dalam penulisan puisi menggunakan model Example Non-Example siswa kelas X SMAN 10 Kota Ternate

2. Wawancara. Menurut Singarimbun \& Effendi, (1995), wawancara merupakan suatu proses interaksi dan komunikasi. Dalam proses ini, hasil wawancara ditentukan oleh beberapa faktor yang berinteraksi dan mempengaruhi arus informasi. Faktor-faktor tersebut ialah, pewawancara, responden, topik penelitian yang tertuang dalam daftar pertanyaan, dan situasi wawancara. Wawancara dilaksanakan secara lisan dalam pertemuan tatap muka secara individual, sumber data yang diwawancarai adalah guru bahasa Indonesia SMA Negeri 10 Kota Ternate

3. Dokumentasi. Menurut Darmadi, (2014) sejumlah besar fakta dan data tersimpan dalam bahan yang berbentuk dokumentasi. Sebagian besar data yang tersediah adalah berbentuk surat-surat, catatan harian, cenderamata, laporan, artefak, foto. dan sebagainya. Dokumentasi merupakan sebuah metode pengumpulan data yang dilakukan dengan mengumpulkan informasi atau dokumentasi yang berkaitan dengan masalah penelitian.

4. Tes penelitian dilakukan sebanyak dua kali yaitu pretest dan posttest. Pretest atau tes awal digunakan untuk melihat hasil tes siswa jika masi ada kesalahan dalam menulis puisi dan nilai yang diperoleh sangat rendah sehingga perlu dilanjutkan diperbaiki pada tes kedua atau posttest. Posttest atau tes akhir adalah untuk melihat hasil kerja siswa adanya peningkatan atau tidak dalam belajar. Bentuk tes-tes yang dimaksud adalah untuk mengaktifkan siswa kelas $\mathrm{X}$ dalam menulis puisi. Instrument tes, lembar kerja siswa dan hasil tes pretest dan posttest siswa.

\section{Teknik Analisis Data}


Teknik analisis data digunakan dalam penilitian ini, adalah teknik deskriptif kuantitatif, dengan maksud untuk mengetahui tingkat kemampuan menulis puisi, menggunakan model Example NonExample.

Menurut Sukmadinata, (2005) analisis data merupakan kegiatan setelah seluruh data dikumpulkan melalui interview dilengkapi dengan data pengamatan dan data dokuman (triangulasi). Data pada pertemuan pertama dicatat dan data pada pertemuan-pertemuan selanjutnya dicatat, disusun, dan dikelompokan secara intensif kemudian diberi kode agar memudahkan dalam analisis data. Rumus untuk menganalisis hasil penelitian dalam menulis puisi dengan menggunakan model Example NonExample yaitu sebagai berukut:

$$
\mathrm{P}=\frac{\mathrm{F}}{\mathrm{N}} \mathrm{X} 100
$$

Keterangan:

$$
\begin{aligned}
& \mathrm{P}: \text { Hasil yang diteliti } \\
& \mathrm{F}: \text { frekuensi jawaban } \\
& \mathrm{N}: \text { jumlah responden } \\
& \text { 100: bilangan tetap. }
\end{aligned}
$$

\section{HASIL PENELITIAN DAN PEMBAHASAN}

\section{Hasil Penelitian}

Penelitian ini dilaksanakan pada tanggal 17 Februari 2020, dengan menggunakan empat teknik penggumpulan data, yaitu observasi, wawancara, tes dan dokumentasi yang dilaksanankan dalam pembelajaran bahasa Indonesia. Hasil penelitian diperoleh dari tes awal dalam menulis puisi, tidak menggunakan model Example non-Example, sedangkan pada tes akhir menulis puisi menggunakan model Example non-Example. Hasil tes dalam bentuk data kuantitatif. Pada tes awal peneliti memaparkan nilai rata-rata dalam menulis puisi tanpa menggunaka model Example dan non-Example dan pada nilai rata-rata pada tes akhir peneliti menggunakan model Example non-Example.

\section{Hasil Observasi}

Hasil observasi pada tes awal diperoleh saat siswa sedang menerima pelajaran bahasa Indonesia tentang menulis puisi. Hasil penelitian ini bertujuan untuk memperoleh data tentang siswa dalam menulis puisi selama menerima pelajaran oleh guru. Pengamatan dilakukan oleh peneliti sebagai observasi. Hal ini dilakukan agar peneliti dapat memahami kondisi dan perilaku siswa saat meneriman pelajaran tentang menulis puisi. Berdasarkan hasil data yang diperoleh saat melakukan observasi pada tes awal hanya sebagian siswa yang aktif selama pembelajaran berlangsung, kebanyakan siswa masih takut dan ragu untuk menggeluarkan pendapat serta kurang fokus saat proses pembelajaran berlangsung sebangkan pada tes akhir diperoleh saat siswa sedang menerima pelajaran bahasa Indonesia tentang menulis puisi denggan menggunakan model Example Non-Example. Hasil observasi ini bertujuan untuk memperoleh data tentang siswa dalam menulis puisi dengan menggunakan model Example dan Non-Example sebagai bahan untuk peningkatkan kemampuan menulis siswa dengan menggunakan gambar sebagai sarana menulis. Pengamatan dilakukan oleh peneliti sebagai observasi dalam menulis puisi. Hal ini dilakukan agar peneliti dapat memahami kondisi dan perilaku siswa saat meneriman pelajaran tentang menulis puisi. Berdasarkan hasil data yang diperoleh saat melakukan observasi pada tes akhir peneliti membagikan gambar kepada siswa dan siswa diminta menuliskan 
puisi berdasarkan gambar yang dibagikan, siswa terlihat bersemangat saat peneliti membagikan gambar dan peneliti meminta siswa untuk menulis sebagian besar siswa aktif selama pembelajaran berlangsung dan bisa untuk diajak kerja sama selama proses pembelajaran berlangsung.

\section{Hasil Wawancara}

Hasil wawancara terbagi atas dua bagian yaitu hasil wawancara kepada guru mata pelajaran bahasa Indonesia dan kepada siswa yang dipilih sebagai responden.

a. Hasil Wawancara untuk Guru

Hasil wawancara yang dilakukan kepada guru mata pelajaran bahasa Indonesia pada tes awal dan tes akhir, dari hasil wawancara pada tes awal tidak semua siswa menyukai mata pelajaran menulis puisi hanya beberapa siswa saja yang menyukai, selain itu disaat mata pelajaran berlangsung tidak semua siswa fokus ketika pelajaran berlangsung. Pada dasarnya pemahaman siswa masih tergolong rendah, diakibatkan karena kondisi lingkungan yang tidak mendukung dan mungkin model pembelajaran yang tidak sesuai dengan pembelajaran sehingga membuat siswa menjadi kurang fokus. Sementara pada tes akhir hasil wawancara tersebut dapat disimpukan bahwa menulis puisi merupakan pelajaran yang lumayan susah bagi siswa namun dengan menggunakan model Example Non-Example, yaitu gambar sebagai medianya sangat cocok bila diterapkan kepada siswa agar siswa dapat berimajinasi saat menulis, hal ini meningkatkan ketertarikan siswa untuk menulis puisi.

b. Hasil Wawancara untuk Siswa

Hasil wawancara yang dilakukan peneliti pada siswa kelas X SMA Negeri 10 Kota Ternate, yang berinisial SA. Dari wawancara pada tes awal tersebut siswa menyarankan agar guru saat menyampaikan materi jangan terlalu cepat agar siswa yang lain juga dapat memahami apa yang disampaikan oleh guru. Sedangkan pada tes akhir yang berinisial SH. Dari wawancara tersebut siswa sangat menyukai menulis puisi dengan menggunakan model Example Non-Example dianggap lebih mudah untuk menulis puisi dibandingkan dengan tidak menggunakannya karena siswa mendapatkan gambaran langsung terkait dengan apa yang akan ditulis.

\section{Hasil Rekapitulasi Nilai Pada Pre Test}

Tabel 1. Rekapitulasi Nilai Pada Pre Test

\begin{tabular}{llcccccccc}
\hline No & \multicolumn{1}{c}{ Nama Siawa } & \multicolumn{9}{c}{ Aspek yang Dinilai } & Jumlah & Nilai & Ket \\
\cline { 2 - 6 } & & $\mathbf{1}$ & $\mathbf{2}$ & $\mathbf{3}$ & $\mathbf{4}$ & $\mathbf{5}$ & & & \\
\hline 1 & Salfira Dewika M Idris & 3 & 2 & 2 & 2 & 1 & 10 & 50 & $\mathrm{~K}$ \\
2 & Irsandy F. Yusuf & 2 & 1 & 2 & 1 & 1 & 7 & 35 & $\mathrm{~K}$ \\
3 & Nurjan Abdrahim & 1 & 1 & 1 & 1 & 3 & 7 & 35 & $\mathrm{~K}$ \\
4 & Risnawati & 3 & 2 & 2 & 2 & 3 & 12 & 60 & $\mathrm{C}$ \\
5 & Mentari Basrin & 2 & 1 & 2 & 2 & 1 & 8 & 40 & $\mathrm{~K}$ \\
6 & Inda Soleman & 2 & 1 & 2 & 2 & 1 & 8 & 40 & $\mathrm{~K}$ \\
7 & Nadya Maya & 2 & 1 & 2 & 2 & 1 & 8 & 40 & $\mathrm{~K}$ \\
8 & Aryo M. Bin Umar & 2 & 1 & 2 & 1 & 1 & 7 & 35 & $\mathrm{~K}$ \\
9 & Sahrul M. Rasio & 2 & 2 & 2 & 3 & 1 & 10 & 55 & $\mathrm{~K}$
\end{tabular}




\begin{tabular}{|c|c|c|c|c|c|c|c|c|c|}
\hline 10 & Dwi Chintya Umafagur & 3 & 2 & 3 & 2 & 1 & 11 & 55 & $\mathrm{~K}$ \\
\hline 11 & Yulianti La Anda & 2 & 2 & 2 & 1 & 1 & 8 & 40 & $\mathrm{~K}$ \\
\hline 12 & Ramly Aswad & 2 & 1 & 2 & 2 & 1 & 8 & 40 & $\mathrm{~K}$ \\
\hline 13 & Ekaindrayani A. Abdul & 2 & 2 & 2 & 2 & 1 & 9 & 45 & $\mathrm{~K}$ \\
\hline 14 & Suci Nabila & 2 & 1 & 1 & 1 & 1 & 6 & 30 & $\mathrm{~K}$ \\
\hline 15 & Sella Armi & 1 & 1 & 1 & 1 & 1 & 5 & 25 & $\mathrm{~K}$ \\
\hline 16 & Eisya Della Putrid & 3 & 2 & 3 & 2 & 2 & 12 & 60 & $\mathrm{C}$ \\
\hline 17 & Sapna Kafau & 2 & 2 & 2 & 2 & 2 & 10 & 50 & $\mathrm{~K}$ \\
\hline 18 & Fildan Farmin & 1 & 1 & 2 & 1 & 1 & 6 & 30 & $\mathrm{~K}$ \\
\hline 19 & Nirma Rusdi & 2 & 1 & 2 & 1 & 1 & 7 & 35 & $\mathrm{~K}$ \\
\hline 20 & Siti Hartina & 2 & 2 & 2 & 2 & 1 & 9 & 50 & $\mathrm{~K}$ \\
\hline 21 & Dewi Astute H. Saubada & 2 & 1 & 2 & 2 & 1 & 8 & 40 & $\mathrm{~K}$ \\
\hline 22 & Fitria Norau & 2 & 1 & 2 & 2 & 1 & 8 & 40 & $\mathrm{~K}$ \\
\hline 23 & Rafly Edy Pau & 1 & 1 & 1 & 1 & 1 & 5 & 25 & $\mathrm{~K}$ \\
\hline 24 & Rastiana Ruslan & 3 & 2 & 3 & 1 & 1 & 10 & 50 & $\mathrm{~K}$ \\
\hline \multirow[t]{3}{*}{25} & Chaedir Vito S.A & 3 & 1 & 2 & 3 & 1 & 10 & 50 & $\mathrm{~K}$ \\
\hline & Jumlah & 52 & 35 & 50 & 41 & 29 & 209 & 1.005 & \\
\hline & Rata-rata & 2,08 & 1,4 & 2 & 1,64 & 1,16 & 8,36 & 40.2 & \\
\hline
\end{tabular}

Aspek yang dinilai:

1. Diksi /pilihan kata

2. Majas/gaya bahasa

3. Pecitraan/imaji

4. Enjambemen

5. Penggulangan bunyi.

Dari uraian tabel 1, penilaian sebagai aspek dalam menganalisis data pada tes awal yaitu: aspek 1, penggunaan diksi/pilihan kata dalam menulis puisi, pada aspek ini rata-rata siswa cukup mampu menggunakan diksi yang sesuai dalam menulis puisi; Aspek 2, Penggunaan majas/gaya bahasa dalam menulis puisi, pada aspek ini rata-rata siswa belum mampu menggunakan majas yang sesuai dalam menulis puisi; Aspek 3, Penggunaan pecitraan/imaji dalam menulis puisi, pada aspek ini rata-rata siswa cukup mampu untuk menggunakan imaji yang sesuai dalam menulis puisi; Aspek 4, Penggunaan Enjambemen dalam menulis puisi, pada aspek ini rata-rata siswa belum mampu untuk menggunakan enjambemen yang sesuai dalam menulis puisi; dan aspek 5, Penggunaan pengulangan bunyi dalam menulis puisi, pada aspek ini rata-rata siswa belum mampu untuk menggunakan pengulangan bunyi yang tepat. Peningkatan kemampuan menulis puisi dengan menggunakan model Example NonExample Siswa Kelas X SMA Negeri 10 Kota Ternate, dari hasil penelitiandapat di klasifikasikan analisis data hasil penelitian, bahwa pada tes awal siswa belum mampu menulis puisi karena belum mencapai (KKM).

\section{Hasil Rekapitulasi Nilai Pada Post Test}

Tabel 2. Rekapitulasi Nilai Pada Post Test

\begin{tabular}{llllllllll}
\hline No & \multicolumn{4}{c}{ Nama Siawa } & \multicolumn{4}{c}{ Aspek yang Dinilai } & \multicolumn{3}{c}{ Jumlah Nilai } & Ket \\
\cline { 3 - 7 } & & $\mathbf{1}$ & $\mathbf{2}$ & $\mathbf{3}$ & $\mathbf{4}$ & $\mathbf{5}$ & & & \\
\hline 1 & Salfira Dewika M Idris & 4 & 4 & 4 & 3 & 1 & 16 & 80 & B \\
2 & Irsandy F. Yusuf & 3 & 2 & 2 & 2 & 1 & 10 & 50 & K \\
3 & Nurjan Abdrahim & 4 & 3 & 4 & 3 & 2 & 16 & 80 & B
\end{tabular}




\begin{tabular}{clcccccccc}
4 & Risnawati & 3 & 3 & 3 & 3 & 1 & 13 & 65 & $\mathrm{C}$ \\
5 & Mentari Basrin & 2 & 3 & 2 & 2 & 1 & 10 & 50 & $\mathrm{~K}$ \\
6 & Inda Soleman & 2 & 2 & 2 & 1 & 1 & 8 & 40 & $\mathrm{~K}$ \\
7 & Nadya Maya & 4 & 3 & 3 & 3 & 1 & 13 & 60 & $\mathrm{C}$ \\
8 & Aryo M. Bin Umar & 2 & 1 & 2 & 2 & 1 & 8 & 40 & $\mathrm{~K}$ \\
9 & Sahrul M. Rasio & 3 & 2 & 2 & 2 & 1 & 10 & 50 & $\mathrm{~K}$ \\
\hline 10 & Dwi Chintya Umafagur & 3 & 3 & 3 & 3 & 1 & 12 & 60 & $\mathrm{C}$ \\
11 & Yulianti La Anda & 3 & 3 & 3 & 3 & 1 & 13 & 65 & $\mathrm{C}$ \\
12 & Ramly Aswad & 4 & 3 & 3 & 3 & 1 & 14 & 70 & $\mathrm{C}$ \\
13 & Ekaindrayani A. Abdul & 4 & 3 & 3 & 3 & 1 & 14 & 70 & $\mathrm{C}$ \\
14 & Suci Nabila & 2 & 2 & 2 & 2 & 1 & 9 & 45 & $\mathrm{C}$ \\
15 & Sella Armi & 4 & 3 & 3 & 3 & 1 & 14 & 70 & $\mathrm{C}$ \\
16 & Eisya Della Putrid & 4 & 4 & 4 & 3 & 2 & 17 & 85 & $\mathrm{SB}$ \\
17 & Sapna Kafau & 3 & 3 & 3 & 3 & 2 & 16 & 80 & $\mathrm{~B}$ \\
18 & Fildan Farmin & 3 & 3 & 2 & 3 & 1 & 14 & 70 & $\mathrm{C}$ \\
19 & Nirma Rusdi & 4 & 3 & 3 & 3 & 1 & 14 & 70 & $\mathrm{C}$ \\
20 & Siti Hartina & 4 & 3 & 4 & 3 & 1 & 15 & 75 & $\mathrm{~B}$ \\
21 & Dewi Astute H. Saubada & 4 & 4 & 4 & 3 & 2 & 17 & 85 & $\mathrm{SB}$ \\
22 & Fitria Norau & 2 & 2 & 2 & 2 & 1 & 9 & 45 & $\mathrm{~K}$ \\
23 & Rafly Edy Pau & 3 & 2 & 3 & 2 & 1 & 11 & 55 & $\mathrm{~K}$ \\
24 & Rastiana Ruslan & 4 & 3 & 3 & 3 & 1 & 14 & 70 & $\mathrm{C}$ \\
25 & Chaedir Vito S.A & 3 & 2 & 3 & 3 & 1 & 12 & 60 & $\mathrm{C}$ \\
& Jumlah & 81 & 69 & 72 & 66 & 29 & 340 & 1.590 & \\
& Rata-rata & 3,24 & 2,76 & 2,88 & 2,64 & 1,16 & 13.6 & 63.6 & \\
\hline
\end{tabular}

Aspek yang dinilai:
1. Diksi /pilihan kata
2. Majas/gaya bahasa
3. Pencitraan/imaji
4. Ejambemen
5. Penggulangan bunyi.

Dari uraian tabel 2, penilaian sebagai aspek dalam menganalisis data pada tes akhir yaitu: Aspek 1, penggunaan diksi/pilihan kata dalam menulis puisi model Example Non-Example, pada aspek ini rata-rata siswa sudah mampu menggunakan diksi yang sesuai; Aspek 2, Penggunaan majas/gaya bahasa dalam menulis puisi dengan mengunakan model Example Non-Example, pada aspek ini ratarata siswa cukup mampu menggunakan majas yang sesuai; Aspek 3, Penggunaan pencitraan/imaji dalam menulis puisi menggunakan model Example Non-Example, pada aspek ini rata-rata siswa sudah mampu menggunakan imaji yang sesuai; Aspek 4, Penggunaan Emanjemen dalam menulis puisi menggunakan model Example dan Non-Example, pada aspek ini rata-rata siswa sudah cukup mampu menggunakan enjambemen yang sesuai; dan aspek 5, Penggunaan penggulangan bunyi dalam menulis puisi menggunakan model Example Non-Example, rata-rata siswa belum bisa menggunakan penggulang bunyi yang tepat. Peningkatan Kemampuan Menulis Puisi dengan Menggunakan Model Example Non-Example Siswa Kelas X SMA Negeri 10 Kota Ternate, dari hasil penelitian dapat di klasifikasikan analisis data hasil penelitian, bahwa pada tes akhir siswa mampu menulis puisi sesuai dengan (KKM). 


\section{Pembahasan}

Hasil penelitian peningkatan keterampilan menulis puisi dengan menggunakan model Example Non-Example siswa kelas X SMAN 10 Kota Ternate yang terdiri dari 25 siswa dapat diketahui bahwa siswa mampu menulis puisi dengan menggunakan model Example Non-Example, hal ini diketahui dari hasil penelitian yang terdapat ada lembar kerja pada Pre Test dan Post Ters mengalami peningkatan.

Tabel 3. Rekapitulasi Nilai Menulis Puisi Siswa Pre Test dan Post Test

\begin{tabular}{clcc}
\hline No & \multicolumn{1}{c}{ Nama Siswa } & Pre test & Post test \\
\hline 1 & Salfira Dewika M Idris & 50 & 80 \\
2 & Irsandy F. Yusuf & 35 & 50 \\
3 & Nurjan Abdrahim & 35 & 80 \\
4 & Risnawati & 60 & 65 \\
5 & Mentari Basrin & 40 & 50 \\
6 & Inda Soleman & 40 & 40 \\
7 & Nadya Maya & 40 & 60 \\
8 & Aryo M. Bin Umar & 35 & 40 \\
9 & Sahrul M. Rasio & 55 & 50 \\
10 & Dwi Chintya Umafagur & 55 & 60 \\
11 & Yulianti La Anda & 40 & 65 \\
12 & Ramly Aswad & 40 & 70 \\
13 & Ekaindrayani A. Abdul & 45 & 70 \\
14 & Suci Nabila & 30 & 45 \\
15 & Sella Armi & 25 & 70 \\
16 & Eisya Della Putrid & 60 & 85 \\
17 & Sapna Kafau & 50 & 80 \\
18 & Fildan Farmin & 30 & 70 \\
19 & Nirma Rusdi & 35 & 70 \\
20 & Siti Hartina & 50 & 75 \\
21 & Dewi Astute H. Saubada & 40 & 85 \\
22 & Fitria Norau & 40 & 45 \\
23 & Rafly Edy Pau & 25 & 55 \\
24 & Rastiana Ruslan & 50 & 70 \\
25 & Chaedir Vito S.A & 50 & 60 \\
& Jumlah & 1.005 & 1.590 \\
& & 40.2 & 63.6 \\
\hline
\end{tabular}

Dari hasil rekapitulasi nilai menulis puisi siswa dengan menggunakan model Example NonExample siswa kelas X SMA Negeri 10 Kota Ternate, pada pre test dengan jumlah nilai 1.005 dengan nilai rata-rata 40.2 dari hasil tes awal sebanyak 23 siswa 92\% tidak mencapai (KKM). Sedangkan pada hasil post test dalam menulis puisi menggunakan model Example-Non Example siswa kels X SMA Negeri 10 Kota Ternate, dengan nilai 1.590 dengan nilai rata-rata 63.6 sebanyak 17 siswa 68\% sudah mencapai (KKM).

\section{SIMPULAN}

Berdasarkan hasil penelitian dan pembahasan yang telah diuraikan sebelumnya dalam pembelajran menulis puis sebagai berikut:

1. Hasil penelitian Peningkatan Keterampilan Menulis Puisi dengan Menggunakan Model Example Non-Example siswa kelas X SMAN 10 Kota Ternate yang terdiri dari 25 siswa dapat diketahui 
bahwa siswa mampu menulis puisi dengan menggunakan model Example Non-Example, hal ini diketahui dari hasil penelitian yang terdapat ada lembar kerja pada pre-test dan post-test mengalami peningkatan.

2. Hasil Observasi menunjukan ternyata pada tes awal siswa belum mencapai standar ketuntasan (KKM) sedangkan pada tes akhir siswa sudah mencapai standar ketuntasan (KKM).

3. Hasil wawancara yang diperoleh dari guru mata pelajaran bahasa Indonesia bahwa dalam kegiatan menulis puisi pada tes awal siswa belum mencapai (KKM) sedangkan pada tes akhir dengan menggunakan model Example Non-Example siswa sudah mencapai (KKM).

4. Hasil tes awal kemampuan menulis puisi siswa kelas X SMA Negeri 10 Kota Ternate menunjukkan bahwa, sesuai dengan standar ketuntasan (KKM) pada mata pelajaran bahasa Indonesia dengan materi menulis puisi siswa belum mencapai (KKM) yang telah ditetapkan , sedangkan pada tes akhir siswa mampu menulis puisi dengan menggunakan model Example NonExample, siswa bisa memperoleh nilai maksimal karena sebagaian besar siswa mencapai (KKM) yang telah ditetapkan.

\section{DAFTAR PUSTAKA}

Aqib, Z. (2013). Model-Model, Media, dan Strategi Pembelajaran Kontekstual (Inovatif). Bandung: yrama widya.

Arikunto, S. (2002). Prosedur Penelitian Suatu Pendekatan Praktek, Cet. Ke-12. Jakarta. Rineka Cipta.

Darmadi, H. (2014). Metode penelitian pendidikan dan sosial. In Bandung: Alfabeta.

Guntur, T. H. (2008). Menulis Sebagai Suatu Keterampilan Berbahasa. In Edisi revisi. Angkasa: Bandung.

Kurniasih, I., \& Sani, B. (2015). Ragam pengembangan model pembelajaran untuk peningkatan profesionalitas guru. In Jakarta: Kata Pena (pp. 71-72).

Moleong, L. J. (2019). Metodologi penelitian kualitatif. Remaja Rosdakarya.

Rahman, M. H. (2017). Using discovery learning to encourage creative thinking. International Journal of Social Sciences \& Educational Studies, 4(2), 98.

Rahman, M. H. (2013). Pedagogical CompetenceJunior High School Science Teacher. Proceedings of the 2nd International Seminar on Quality and Affordable Education (ISQAE 2013), 383-388.

Rahman, M. H., \& Ahmad, Z. (2017). Kompetensi Guru IPA SMP Pulau Bacan Kabupaten Halmahera Selatan. Humano: Jurnal Penelitian, 7(2), 207-216.

Rahman, M. H., \& Latif, S. (2020). Pengembangan Bahan Ajar Tematik Terpadu Berbasis Problem Based Learning Untuk Meningkatkan Kemampuan Berpikir Kritis Siswa SD Kelas V. EDUKASI, $18(2)$.

Singarimbun, M., \& Effendi, S. (1995). Metode Penelitian Survai Edisi Revisi. In Jakarta: Lp3ES.

Sugiyono, S. (2013). Metode Penelitian Kualitatif. Alfabeta.

Suhartono, T. (2012). Pengaruh Media Kartu Kata terhadap Kemampuan Menulis Kreatif Puisi Kelas VII SMPN 249 Jakarta Barat. Universitas Negeri Jakarta.

Sukmadinata, S. N. (2005). Metode Penelitian Pendidikan. In Bandung: PT remaja rosdakarya.

Wardhana, W. A., \& Ardianto, A. S. (2007). Menyingkap rahasia jadi penulis. Pustaka Pelajar. 